\title{
Cuentos de Grimm y cuentos tradicionales españoles
}

\author{
María del Carmen Alonso ÍmaZ \\ Universidad Rey Juan Carlos \\ mariacarmen.alonso.imaz@uric.es
}

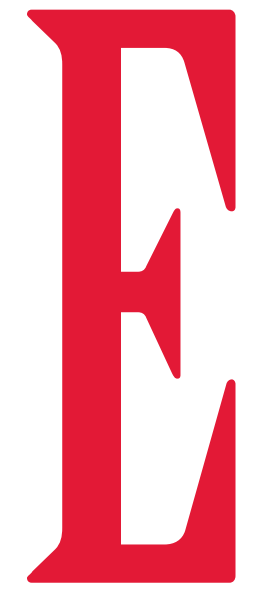

$\mathrm{n}$ este trabajo hemos analizado la relación existente entre algunos cuentos de origen popular recogidos en su día por los hermanos Grimm y otros arraigados en el folklore y la literatura españoles. Para ello hemos partido del estudio de Bolte y Polívka, Anmerkungen zu den Kinder-und Hausmärchen der Brüder Grimm $^{(1)}$, obra de enorme utilidad para la investigación sobre el cuento y para el estudio de la literatura comparada de estos materiales. Las anotaciones a los cuentos de Grimm se publicaron en 1812 y 1815 como anexo a los dos primeros tomos de la primera edición, más tarde en un tomo especial en 1822 y en una tercera edición de 1856. Hermann Grimm le había entregado a Bolte los ejemplares manuscritos por su padre y su tío. Al estudio de Bolte se sumó el de Polívka, gran conocedor de la literatura popular de las ramas eslavas del Este y Sudeste de Europa y de las caucásicas y centralasiáticas.

En nuestro análisis seguimos la clasificación habitual del cuento en términos universales, conforme a la tipología clásica de Aarne-Thompson, que establece cinco grandes categorías: cuentos de animales, cuentos comunes (maravillosos / religiosos / novelescos / del ogro tonto), chistes y anécdotas, cuentos formulísticos y cuentos inclasificados. Así mismo, nos ceñimos a los motivos que establece Aarne-Thompson en su clasificación ${ }^{(2)}$.
Los cuentos aquí seleccionados pertenecen al grupo de los denominados "cuentos comunes". Tras proceder a su resumen argumental, nos referimos a los motivos que los integran, así como a su correspondencia con narraciones o fábulas de diverso origen.

Presentamos, por último, su variante o variantes en el folklore oral español y/o en otras lenguas peninsulares documentadas en el Catálogo tipológico del cuento folklórico español de Camarena y Chevalier ${ }^{(3)}$, repertorio que abarca las cuatro grandes áreas lingüísticas españolas: castellano, catalán, gallego y vasco, y cuyos cuentos clasificados entre los números T. 300 y T.749 presentan un esquema común a todos los cuentos de héroe, maravillosos o no: el héroe padece una carencia/agresión y se aleja del hogar familiar. En el camino recibe de un donante algo maravilloso, o alguien le auxilia. Conseguirá superar las pruebas prematrimoniales y casarse con la princesa, o vencer al dragón/gigante.

\section{El pájaro de oro (Der goldene Vogel) (G.57)}

En El pájaro de oro, la narración parte del asombroso suceso de cómo los frutos del hermoso peral que hay delante del palacio del rey desaparecen cada año en una sola noche, sin saberse quién los roba.

El rey encarga al mayor de sus tres hijos que vigile el peral todas las noches durante un año entero hasta descubrir

(1) BOLTE, J. y POLÍVKA, G. (1913-1918): Anmerkungen zu den Kinder- und Hausmärchen der Brüder Grimm. 3 vols. Dieterich'sche Verlagsbuchhandlung Theodor Weicher. Leipzig.

(2) AARNE Y THOMPSON (1910): The Types of the Folktale. Verzeichnis der Märchentypen. FF Communications, 3. Helsinki.

(3) CAMARENA, J. y CHEVALIER, M. (1995): Catálogo tipológico del cuento folklórico español. Gredos. Madrid.

(4) Citamos los cuentos de Grimm anteponiendo la mayúscula G a cada número de cuento, siguiendo siempre el orden del manuscrito completo de los cuentos de Grimm que manejaron Bolte y Polívka. 


\section{Resumen:}

Nos hemos centrado en dos cuentos tradicionales populares recogidos por los hermanos Grimm, El pájaro de oro y El agua de la vida, dos "cuentos comunes", --según la clasificación de Aarne-Thompson--, conforme a cuyo esquema marcha el héroe de casa, debido a una necesidad imperiosa o a una agresión, y en el camino recibe de un donante algo maravilloso gracias a lo cual podrá superar una serie de difíciles pruebas y ganar a la princesa. Una vez mostrados su argumento, los motivos que los conforman y su correspondencia con narraciones de diverso origen, presentamos las variantes de ambas narraciones que hemos hallado en la literatura popular española - documentándonos para ello en el catálogo tipológico de Camarena y Chevalier--. Analizada la correspondencia entre Der goldene Vogel (El pájaro de oro) con sus variantes populares españolas Las tres maravillas del mundo y La perera, y de Das Wasser des Lebens (El agua de la vida) con las de El castillo de Irás y no Volverás, hemos concluido en la coexistencia entre las narraciones españolas y las alemanas de algunos rasgos comunes, además de argumento, estructura y motivos, a saber varios elementos recurrentes, como son la conversación entre espíritus, animales o brujas, y la repetición del número mágico tradicional 3; en segundo lugar, en el antiquísimo origen de estos cuentos en el espacio y en el tiempo, remontándose hasta la Antigüedad, aunque habiéndose adaptado las variantes a la idiosincrasia de los lugares; por último, en que, aunque los rasgos de crueldad propios de las sociedades primitivas están generalmente presentes en los cuentos de Grimm, sin embargo en estos dos cuentos estudiados y en sus correspondientes variantes en lenguas hispánicas destacan, junto al fin moralizante, el perdón y la ausencia de venganza.

Palabras clave: cuento de Grimm - esquema - variante - narración literatura popular - catálogo - correspondencia - motivo - héroe - origen - tradición

\section{Zusammenfassung:}

Wir haben uns in unserer Betrachtung auf zwei Hausmärchen der Brüder Grimm konzentriert, und zwar auf Den goldenen Vogel und Das Wasser des Lebens, zwei alltägliche Märchen gemä $\beta$ der Aaarne-Thompson Klassifizierung des Märchens. Nach dessen üblichem Schema geht der Held wegen eines Mangels oder eines Angriffs von zu Hause fort. Auf seinem Weg bekommt er von einem Gönner irgendeine wundervolle Gabe, so dass er eine ganze Reihe schwieriger Prüfungen überwinden kann und es ihm endlich gelingt, die Prinzessin zu gewinnen. Nachdem der Inhalt und die Motive, aus denen beide Märchen bestehen, sowie die Verwandtschaft mit Erzählungen unterschiedlicher Herkunft analysiert worden sind, präsentieren wir die jeweiligen Varianten dieser zwei Grimm'schen Märchen, die wir in der hispanischen traditionellen Literatur gefunden haben, wozu wir uns auf die Typisierung und das Repertoire der spanischen volkstümlichen Märchen von Camarena und Chevalier bezogen haben--. Nach der Analyse der Beziehung zwischen Dem goldenen Vogel (El pájaro de oro) und seinen jeweiligen volkstümlichen spanischen Varianten Las tres maravillas del mundo und La perera, und von Dem Wasser des Lebens (El agua de la vida) und seinen verschiedenen spanischen Varianten von El castillo de Irás y no Volverás, sind wir zu folgendem Schluss gekommen: Es gibt Übereinstimmungen in den hispanischen und den deutschen Erzählungen: Erstens entsprechen sich nicht nur Thema, Struktur und Motive, sondern auch verschiedene wiederkehrende Elemente, wie z. B. Gespräche zwischen Geistern, Tieren oder Hexen, oder die Wiederholung der traditionellen magischen Zahl drei; zweitens geht der Ursprung dieser Märchen bis auf die Antike zurück, obwohl sich ihre Varianten oft an die Eigenart des Landes angepasst haben. Abschließend ist auch interessant festzustellen, dass es, obwohl Grimm'sche Märchen sehr oft die grausamsten Charakterzüge des Menschen der primitiven Gesellschaft aufweisen, in diesen beiden Märchen und in ihren jeweiligen spanischen Varianten eine moralische Absicht gibt, und statt Rachgier ist hier die Rede von Vergebung und Gutherzigkeit.

Schlüsselwörter: Grimm'sche Märchen - Schema - Variante - Erzählung volkstümliche Literatur - Katalog - Verwandtschaft - Motiv - Held - Herkunft - Überlieferung

último hilo de la tela se transforma en una bella princesa, a la que también él resulta haber liberado. Se casa con la princesa y se convierte en un rico rey.

He aquí los motivos de este cuento:

A. Un rey, enfermo incurable, oye/sueña con un pájaro (fénix) cuyo silbido/canto puede curarle.

B. Sus tres hijos marchan a buscar el medio curativo/ pájaro/flor/fruto milagroso.

C. Sólo el más joven de los tres hijos consigue, con ayuda de un zorro encantado/un enano/una vieja, alcanzar el pájaro de oro, e incluso un buen caballo y a una bella joven. 
D. Por envidia, sus hermanos mayores deciden robarle y lanzarle a un pozo, pero el zorro le salva.

En bastantes variantes aparece una parte introductoria donde el rey enfermo/ciego está desahuciado, pero oye/ sueña con un ave fénix cuyo silbido/canto podría curarle, a lo que sus tres hijos marchan uno tras otro a la búsqueda del ave. Las distintas versiones difieren sólo en la cantidad de tareas que ha de realizar el tercer hijo.

La versión más antigua es el poema danés del siglo XVI de los tres príncipes Carlos, Guillermo y Artús, del que derivan la historia islandesa en prosa (1691) y la sueca (1701). La holandesa, poco conocida, coincide con el "Roman von Walewein" neerlandés, traducido de un poema francés perdido, donde el rey Artús no busca un medio curativo, sino un lujoso tablero de ajedrez, que marcha a buscar su sobrino Walewein. Éste llega a un país cuyo rey le exige a cambio la espada del rey Amoris auf Ravensten. Éste le pide, a su vez, que le entregue a la bella hija del rey Assentin de la India. Walewein consigue entrar en el palacio de Assentin con la ayuda del príncipe Roge, convertido en zorro encantado, y la doncella Isabele reconoce en él al caballero soñado: pretende huír con él, pero ambos son apresados. Finalmente son liberados gracias al espíritu del caballero encarnado, que así agradece al héroe que le hubiera dado cristiana sepultura. Cuando Walewein, fiel a su juramento, va a entregar a su amada Isabele al rey Amoris auf Ravensten, éste ha muerto, tras lo que él regresa a su país feliz y contento con la doncella y con el tablero de ajedrez, que consiguió a cambio de la espada mágica.

Encontramos aquí el motivo del héroe que debe entregar unos tesoros a cambio del objeto deseado y al fin conseguido, así como el motivo del zorro servicial, aunque no el de la medicina para el padre, ni tampoco el de los hermanos envidiosos, -que sí está, en cambio, en cuentos más modernos- ${ }^{(5)}$.

\subsection{Variantes de El pájaro de oro (Der goldene Vogel) en el folklore oral español}

En el folklore oral español hemos hallado las dos variantes siguientes: T. 550: [La búsqueda del pájaro dorado]: Las tres maravillas del mundo y T. 301A: [Búsqueda de la princesa desaparecida]: La perera ${ }^{(6)}$ (El peral).

\subsubsection{La búsqueda del pájaro dorado: Las tres maravillas del mundo (T. 550)}

Un rey enfermo sólo sanará con las tres maravillas del mundo. Marcha el hijo mayor a buscarlas, pero le atrapan unos ladrones; igual le sucede al segundo. Por último marcha el tercero.

Llega a la cueva del aire; la madre de los aires le esconde para que su hijo el aire no lo devore. Cuando llega, dice oler a carne cristiana y quiere comérselo; finalmente se aplaca y le indica que marche adonde su hermano el sol. Allí otra vieja le esconde para que no le abrase su hijo, el sol; éste también huele la carne cristiana, pero se apiada y le envía adonde su hermana la luna. Ésta le quiere devorar, mas luego se calma y le envía hacia su hermano el rey de las aves. Éste dice que tal vez pueda indicarle el camino alguna de sus aves, que vuelan por todo el mundo, y manda llamar a una pareja de cada clase de aves. El joven les va preguntando, hasta que un águila coja dice saberlo, y se compromete a llevarle donde las tres maravillas del mundo a cambio de que le dé a comer mucha carne. Él mata a su caballo, se monta en el águila y le va dando de comer trozos de carne del caballo todo el camino. Acabada la carne, se ofrece a cortarse un trozo de su propia nalga, pero el águila rechaza la carne de cristiano. Ya en tierra, le indica cómo llegar hasta el castillo de las tres maravillas.

El héroe pide posada en una casa, a cuya dueña le costea el entierro de su marido. Ya en el castillo, le sale al encuentro una raposa y le indica que de todos los objetos que hay allí -un pájaro, una jaula, una dama, una cama y un caballo en la cuadra- sólo debe coger uno. Él toma el pájaro con su jaula; al punto le sale al paso el gigante que guarda el castillo, le da una paliza y le mete en el calabozo. De allí le saca la raposa, advirtiéndole que sólo podrá sacarle una vez más.

La segunda vez saca solamente el caballo; fuera aguardan ya las tres maravillas del mundo, que son el caballo, la dama y el pájaro: él monta el caballo con la montura, la dama

(5) V.gr., en la siguiente parábola provenzal: Un rey, enfermo incurable, sabe que sólo puede sanar con el agua de la vida. Por ello, llama a sus tres hijos y promete su reino a quien le consiga el agua de la juventud. Los tres se reparten la tierra para vigilarla: el mayor, las orillas; el segundo, las llanuras; el menor, las montañas. Un anciano explica al menor los peligros que habrá de superar: en primer lugar tendrá que matar a una serpiente; luego tendrá que luchar contra la belleza de las doncellas, a las que no podrá mirar. Se tropezará con caballeros y barones que le ofrecerán armas de todo tipo, pero él no podrá tocarlas. La última prueba consistirá en abrir con la llave el palacio donde se halla la doncella, en cuya puerta hay unas campanas que suenan cuando se acerca alguien, y al momento salen caballeros a matar al intruso. El joven supera las diferentes pruebas: al llegar a palacio, tapa con una esponja las campanas y entra; la bellísima doncella que hay dentro del palacio le da agua y le dice que el caballero valiente que consiguiera entrar estaba destinado a ser su esposo.

(6) Citamos los cuentos recogidos del folklore español anteponiendo la mayúscula T ("cuento tipo"), conforme a la clasificación que hacen Camarena y Chevalier (1995). 
vestida con sus ropas y el pájaro en su jaula. En el camino de vuelta, sus dos hermanos le arrebatan las maravillas, se las llevan a su padre, le curan y luego difaman al hermano como ladrón y asesino. El padre ordena traerle vivo o muerto, y cuando llega lo mete en el calabozo. Pero la raposa se presenta bajo la forma de un hombre y revela al rey que fue él quien buscó las tres maravillas del mundo; también el difunto cuyo entierro pagó el joven aparece y cuenta el gran servicio que le hizo. El rey deshereda a los hermanos mayores y nombra heredero al pequeño, que se casa con la dama ${ }^{(7)}$.

\subsubsection{Búsqueda de la princesa desaparecida: La perera (El peral)(8) (T.301A)}

Esta segunda variante en el folklore oral español refiere cómo un padre de tres hijos posee un peral que da unas hermosísimas peras. Encarga al hijo mayor que vigile hasta averiguar por qué cada noche desaparece una pera, pero aquél se duerme; igual le sucede al segundo hijo. La tercera noche vigila el tercero, y ve cómo un pajarraco negro se lleva rápido la pera, metiéndose con ella en un pozo muy hondo. Corre a casa a contarlo, a lo que marchan todos a matar al pájaro. El hermano mayor se hace bajar el primero al pozo, atado con una cuerda, pero a mitad del descenso manda que le suban; el segundo baja algo más, pero también fracasa en el intento.

El tercero logra llegar abajo y halla tres puertas: de la primera sale una vieja de enormes dientes; él le pregunta por el pájaro negro que roba las peras, y ella le envía a la puerta de al lado, avisándole de que vive allí un gigante asesino. El joven vence al gigante con una espada oxidada, $\mathrm{y}$ al otro lado de la puerta halla un hermosísimo palacio, en apariencia deshabitado, pero desde cuyo interior clama una voz de mujer, rogándole que pregunte a la vieja cómo desencantarla. Ésta no consiente en contestarle, hasta que él con su espada le rompe un diente en mil pedazos: entonces ella le dice que para desencantarla ha de matar al negro que vive tras la tercera puerta. Una vez desencantada la princesa, la ata con la cuerda, toca la campanilla para que sus hermanos la suban, y éstos la llevan a la casa del padre, pero olvidándole a él en el fondo del pozo.

El héroe le parte entonces con la espada otro diente a la vieja, que queda desencantada y resulta ser una hermosa joven, que le indica cómo salir de allí por un agujero del tamaño de una aguja. Tras ellos sale un montón de gente que estaba también encantada. Al llegar a casa se encuentra con que su hermano mayor va a casarse con la princesa, pero el padre dictamina que sea ella quien escoja con quién casarse. Entonces ella elige al que la liberó del encantamiento, y así el héroe deviene en príncipe ${ }^{(9)}$.

\section{El agua de la vida (Das Wasser des Lebens)}

Queremos en segundo lugar destacar el estrecho parentesco existente entre el arriba analizado El pájaro de oro (G. 57) y El agua de la vida (Das Wasser des Lebens) (G. 97), éste último muy extendido por Europa y por Oriente.

El motivo del agua de la vida, que da nombre a este cuento, aparece en una narración armenia, donde un rey envía a sus tres yernos a buscarla; en un cuento escocés van a buscarla las hijas de la reina enferma; en el vasco y en el griego, el rey pide un agua milagrosa para sus ojos; en uno de Gascuña, lo que el rey pide es un vino que le devuelva la juventud. En otras variantes, el medio curativo es la leche de cierva/yegua/osa/zorra /pájaro..., o la sangre de dragón, o la grasa de zorro, o bien se trata de naranjas, cerezas o huevos... En una narración checa, el rey rejuvenece veinticinco años tras leer el libro de oro que el menor de sus hijos le trae del palacio de la bella durmiente ${ }^{(10)}$.

Aquí también aparece el motivo de los tres príncipes a la búsqueda de un remedio curativo (pájaro milagroso/flor/ fruto/agua) para su padre enfermo, consiguiéndolo sólo el hermano más joven, ayudado por un zorro encantado/un enano/una vieja... ${ }^{(11)}$

En la primera variante de El agua de la vida (Das Wasser des Lebens), marchan los tres hermanos a buscar el agua de la vida para el rey moribundo. Los dos mayores malgastan el dinero en el viaje, y en una ciudad roban un tesoro y son encarcelados. Después marcha el hijo menor, y al saber que van a ahorcar a sus dos hermanos, ruega que aguarden a que él vuelva de hacer una diligencia. Llegado hasta un bosque, donde su caballo ya no puede seguir, pregunta a un gigante cómo hacer para hallar el agua de la vida. Éste le dice que quizá lo sepan los conejos y los zorros: son unos

(7) Existen versiones orales en el área lingüística del castellano, catalán, gallego; hay correlación con índices hispanoamericanos: cuatro versiones estadounidenses y seis mexicanas; también portuguesas.

(7) Existen versiones orales en el área lingüística del castellano, catalán, gallego; hay correlación con índices hispanoamericanos: cuatro ves
(8) Versión publicada por F. Maspons y Labrós (1871-1875): La Rondallayre. Quentos populars catalans. A. Verdaguer. Barcelona. I: 94-97.

(9) Hay versiones orales en el área lingüística del castellano, catalán y vascuence; correlación con los otros índices hispanoamericanos (8 versiones estadounidenses, 7 mexicanas, 1 costarricense, 1 guatemalteca; 8 portorriqueñas y 1 chilena); versión portuguesa -según documentan Bolte y Polívka (1913-18)-.

(10) Bolte y Polívka (1913-18).

(11) Existen variantes en portugués y en vasco. 
trescientos, pero no lo saben. Entonces le indica que tal vez lo sepa su hermano, que vive a 300 millas. Un viejo zorro le lleva hasta él, que tampoco lo sabe, y pregunta a su fuego y a sus vientos; lo sabe el viento del Norte, y le lleva hasta un palacio que sólo es visible entre las once y las doce, y que al punto se hunde en el agua.

El héroe llega hasta una lujosa habitación donde duerme una hermosa doncella; después, a la de otra joven más bella; por último, a una aún más lujosa donde se encuentra una tercera doncella aún más hermosa. Yace con ella y deja escritos en una hoja su nombre y la fecha ${ }^{(12)}$. De debajo de su almohada coge tres llaves, con ellas baja al sótano y llena tres botellas de agua. Al salir por la puerta dan las doce y el castillo desaparece.

El viento del Norte le lleva de regreso hasta el bosque donde dejó su caballo, y entra en la ciudad a tiempo de liberar de la horca a sus dos hermanos. Éstos le traicionan en el viaje de vuelta, le cambian el agua de la vida y le calumnian, haciendo creer a su padre que le ha querido envenenar; es desheredado por éste y condenado a muerte; no obstante, su verdugo le perdona la vida. Permanece escondido en el bosque hasta que la princesa, que busca al padre de su hijo, prueba la culpabilidad de los calumniadores. El rey le perdona y él se casa con la princesa. En una segunda variante -donde, por cierto, no aparece el motivo de la princesa liberada- el rey, para descubrir cuál de sus tres hijos es inocente, manda hacer tres alfombras, una de oro, otra de plata y otra corriente. El que cabalgue sobre la de oro será el inocente, y resulta ser el menor.

En una tercera variante, los tres hermanos príncipes viajan juntos. Un pescador les informa de que podrán alcanzar el castillo encantado cuando cada uno de ellos haya conseguido tres plumas del halcón que viene cada tres días y deja caer una.

Una vez en el castillo, deberán luchar con un dragón de siete cabezas: quien en tres días no le haya vencido quedará convertido en piedra; quien le mate, recibirá el agua de la vida. Consiguen entrar en el castillo con las plumas de halcón, y se organiza el combate, al que asiste la Corte entera. Los dos hermanos mayores son vencidos y petrificados. El menor siega de un golpe las siete cabezas. La princesa le entrega el agua de la vida, y él hace revivir con ella a sus hermanos.

\section{1. Variante de El agua de la vida en el folklore oral español: Los hijos en busca de un remedio maravilloso para su padre: El castillo de Irás y no Volverás (T. 551)}

En esta variante del cuento recogida en el folklore oral español bajo el nombre de Los hijos en busca de un remedio maravilloso para su padre: El castillo de Irás y no Volverás (T. 551) ${ }^{(13)}$-que difiere de El agua de la vida en que en ella no hay embarazo de la princesa- el diferente comportamiento para con los animales por parte del hermano menor hace que éstos le brinden su ayuda en prueba de su agradecimiento, de modo que consigue el agua y desencanta a la princesa y a cuantos habían sido petrificados al ir a buscar el agua.

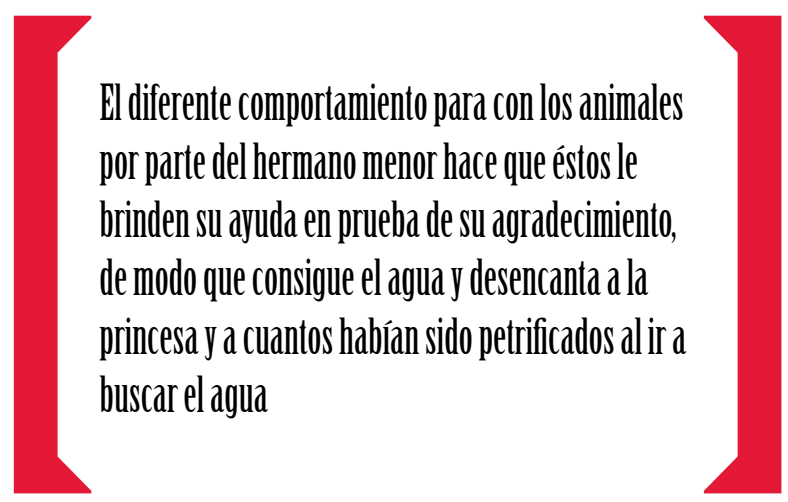

El cuento relata cómo un rey enferma, y los médicos dictaminan que solamente sanará con el agua del castillo de Irás y no Volverás.

Marchan a buscar el agua los dos hermanos mayores, y no dejan ir al pequeño porque le consideran un inútil. Por el camino ven un hormiguero y matan a las hormigas, después tratan de pescar un pez, pero se les escapa con el anzuelo clavado; intentan también cazar una paloma, pero ésta huye herida. Llegados al castillo, el ogro les dice que les dejará coger agua si encuentran todas las perlas del collar que la princesa esparció por el bosque, así como el anillo que se le cayó al lago. Pero como no lo consiguen, les convierte en estatuas de piedra.

El hermano menor marcha a averiguar la suerte de sus hermanos. Por el camino, da de comer a las hormigas, le quita el anzuelo al pez y le cura la herida a la paloma. Una vez llegado al castillo, llora al saber las difíciles condiciones que le exige el ogro a cambio del agua, pero entonces los 
animales, agradecidos, le ayudan: las hormigas le buscan las perlas, y el pez el anillo de la princesa. El ogro le dice que aún le falta quitarle a la princesa la corona que lleva sobre su cabeza. Y aunque eso parece imposible, porque la princesa está en lo alto de una torre sin escaleras, la paloma se la trae. Al instante se desencantan la princesa y todos cuantos habían sido petrificados por haber ido a buscar el agua, entre ellos sus hermanos.

Pero los hermanos mayores engañan al menor, le arrebatan el agua, le maltratan y le cortan una oreja, que la princesa recoge y se guarda. De vuelta donde el rey, éste sana con el agua milagrosa que le dan sus dos hijos mayores. Da a elegir marido a la princesa, y ella escoge al menor de los tres, y le cuenta al rey la verdad de todo, mostrándole la oreja como prueba, a lo que el rey nombra heredero al menor, que se casa con la princesa y perdona a sus hermanos ${ }^{(14)}$.

Este mismo motivo de la petrificación de los dos príncipes mayores aparece en la tercera variante del cuento de Grimm, en la que asimismo el hermano menor vence al dragón, sesgando de un golpe sus siete cabezas, y recibe de manos de la princesa el agua de la vida, con la que hace revivir a sus hermanos ${ }^{(15)}$.

\section{Motivos recurrentes en otros cuentos de Grimm}

Observamos que tanto en El pájaro de oro como en El agua de la vida se cumplen varios elementos habituales: en primer lugar, existen ciertos motivos recurrentes en otros cuentos, vgr. la conversación entre espíritus (o animales o brujas), a partir de la cual quien escucha descubre importantes misterios.

En segundo lugar, aparece repetidamente el número 3, uno de los números mágicos tradicionales. Así, tanto en El pájaro de oro como en sus variantes en la tradición oral española, el tema básico es el de tres príncipes hermanos a la búsqueda de un medio curativo para su padre enfermo, de los cuales el menor resulta siempre ser el héroe triunfador.

También en la primera variante de El agua de la vida pregunta el héroe tres veces por el agua de la vida: primero, a un gigante; después a los conejos y a los zorros; en tercer lugar, al viento del norte. Entra en tres habitaciones sucesivas, donde duermen tres doncellas, bajo la almohada de la tercera de las cuales, con la que yace, encuentra tres llaves y tres botellas de agua. En una segunda variante del cuento el rey manda hacer tres alfombras: una de oro, otra de plata y una común. En la tercera, los príncipes alcanzarán el castillo encantado si consiguen tres plumas del halcón que viene cada tres días, y deberán luchar con un dragón de siete cabezas -aquí encontramos otro de los números recurrentes, el 7- y vencerle en tres días.

En la variante del folklore español El pájaro de oro, Las tres maravillas del mundo, como su propio título indica son tres las maravillas que se buscan, y el héroe llama sucesivamente a tres cuevas: la del aire, la del sol y la de la luna. En la otra variante tradicional española, Búsqueda de la princesa desaparecida, El peral, el héroe, una vez llegado al pozo, va llamando también sucesivamente a tres puertas. Otros números mágicos recurrentes en Grimm son el 9 y el 12 -por ejemplo, el castillo desparece a las 12 en punto-; a veces también el número 7 .

\section{Origen remoto en el espacio y en el tiempo}

Algunos cuentos de Grimm, y entre ellos los dos aquí expuestos junto a sus variantes, El pájaro de oro y El agua de la vida, parecen tener un origen remotísimo, tanto en el tiempo como en el espacio. Así lo demuestran los siguientes motivos e imágenes comunes:

Si en la Antigüedad se fabula con el ave fénix, en las distintas variantes aparece un pájaro de oro o un ruiseñor que canta. No se sabe hasta qué punto puede estar relacionado el cuento, en sus primitivas etapas, con una narración de las 1001 noches. En las variantes griegas, eslavas y armenias se busca al ruiseñor porque sin él queda inacabada la iglesia o la mezquita, lo que entronca con la costumbre, en egipcios, griegos y romanos, de colocar un águila delante del templo.

El motivo del agua de la vida era ya conocido en la poesía persa. También en el paraíso de la Biblia aparece la imagen del árbol de la vida y las manzanas de la vida.

(14) Existen versiones orales dentro de la Península en el área lingüística del castellano; hay correlación con índices hispanoamericanos (una versión hispana de EEUU, dos mexicanas, dos costarricenses y una panameña, seis dominicanas, cinco portorriqueñas, una chilena, tres argentinas y una uruguaya); hay también una versión portuguesa.

(15) Esta misma variante presenta en común con Los tres pajarillos (Drei Vügelken) (G.96) el motivo de la petrificación y resurrección mediante el agua milagrosa, en tanto que la hermana compra el agua de la vida para liberar a su hermano convertido en piedra. 
En cuanto a las variantes existentes en el folklore español, se han adaptado en cierta medida a la idiosincrasia del lugar. Llama la atención en este aspecto el detalle, en Las tres maravillas del mundo, de cómo los distintos elementos -el, aire, el sol, la luna-, así como el águila que le transporta por los aires, insisten en rechazar comer carne de cristiano, posiblemente debido al histórico choque cultural entre las distintas religiones peninsulares.

\section{Rasgos de crueldad propios de una sociedad primitiva}

Sabido es que muchos de los cuentos de Grimm presentan un gran primitivismo, con crueldad, ferocidad y canibalismo, probablemente debido a su raíz antigua y eminentemente popular. Un ambiente general de miseria caracteriza gran parte de los cuentos de Grimm, remite a veces a símbolos remotos, a menudo de carácter universal, en un mundo pleno de fantasía a la par que de extrema pobreza, cuyos personajes actúan movidos por elementos básicos para subsistir en medio del hambre, del frío y la mayor penuria. Todo ello da lugar a numerosos episodios propios de una sociedad primitiva, en un ambiente sórdido que representa el egoísmo y la maldad del ser humano a todos los niveles, sucediéndose los actos más horrendos: asesinato, traición, mutilación, canibalismo, abandono de los hijos en el bosque..., siempre partiendo de unos personajes movidos por los celos, la envidia, el odio, la avaricia, la lujuria...

Si bien aparece un episodio de mutilación en la variante del folklore español El castillo de Irás y no Volverás, donde los hermanos mayores maltratan al menor y le cortan una oreja, es la traición -derivada de los celos y la envidia- el rasgo más destacable, concretamente la envidia hacia el hermano menor y la superioridad sobre él de los hermanos mayores ${ }^{(16)}$. La traición se presenta en el supuestamente idílico círculo familiar, si bien al término aparece siempre el triunfo del bien representado en la figura del héroe. Aunque en Grimm suele ir siempre acompañado del correspondiente castigo del mal, es de notar que en los cuentos aquí analizados, así como en sus variantes del folklore español, el héroe perdona en todos los casos a sus hermanos y no toma venganza de ellos. Se trata de unos de los pocos cuentos de Grimm donde el perdón prima sobre la venganza, que no existe. El castigo del mal se presenta únicamente en cuanto que se deshereda a los hermanos traidores (La búsqueda del pájaro dorado) y en todo caso en la pérdida de aquellos bienes que se obtuvieron por malas artes.

\section{Fin moralizante}

Aunque en Grimm no siempre el final del cuento es feliz, sí suele haber de cualquier forma un fin moralizante, como es aquí el caso, donde triunfa el bien y donde el malvado, si no recibe un castigo ejemplar, al menos es descubierto. Así sucede cuando el héroe, en la variante $E I$ castillo de Irás y no Volverás, recibe el merecido premio a los favores que en su día otorgó, a saber la ayuda, decisiva para su difícil empresa, de los animales agradecidos, a los que sus hermanos maltrataron y él en cambio ayudó o curó altruistamente. El pago a un favor otorgado por el héroe se repite en la variante holandesa de El pájaro de oro, donde el espíritu del caballero agradece al héroe el haberle dado cristiana sepultura, así como en la versión del folklore español Las tres maravillas del mundo, donde el héroe paga el entierro del difunto marido de la mujer en cuya casa se le da posada, acción por la que luego es recompensado.

Bibliografía

AARNE Y THOMPSON (1910): The Types of the Folktale. Verzeichnis der Märchentypen. FF Communications, 3. Helsinki.

ALONSO ÍMAZ, M.C. (2011): Estudio contrastivo entre los cuentos germánicos recogidos por los hermanos Grimm y los cuentos tradicionales españoles en su vertiente popular. Dykinson. Madrid.
BOLTE, J. y POLÍVKA, G. (1913-1918): Anmerkungen $\mathrm{zu}$ den Kinder- und Hausmärchen der Brüder Grimm. 3 vols. Dieterich'sche Verlagsbuchhandlung Theodor Weicher. Leipzig.

CAMARENA, J. y CHEVALIER, M. (1995): Catálogo tipológico del cuento folklórico español. Gredos. Madrid.
HERNÁNDEZ, I., SÁNCHEZ, P. (eds.) (2014): Los cuentos de los hermanos Grimm en el mundo. Recepción y traducción. Síntesis. Madrid.

JOOSEN, V., LATHEY, G. (eds.) (2014): Grimm's Tales around the Globe. The Dynamics of their Internacional Reception. Wayne State Univ. Press. Detroit. 